\title{
USE OF HISTORICAL AERIAL IMAGES FOR 3D MODELLING OF GLACIERS IN THE PROVINCE OF TRENTO
}

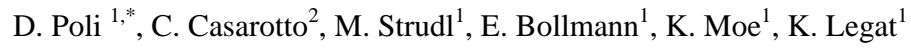 \\ ${ }^{1}$ Vermessung AVT-ZT-GmbH, Eichenweg 42, 6460 Imst, Austria - (d.poli, ma.strudl, e.bollmann, k.moe, k.legat)@avt.at \\ ${ }^{2}$ Museum of Science - Glaciology Group, Trento, Italy- christian.casarotto@muse.it
}

Commission II, WG II/10

KEY WORDS: Historical images, Dense image matching, Glaciers, Change analysis

\begin{abstract}
:
Historical aerial images represent a source of information of great value for glacier monitoring, as they cover the area of interest at a well-defined epoch and allow for visual interpretation and metric analysis. Typically, the aerial images are used to produce orthophotos and manually digitize the perimeters of the glaciers for analysis of the surface extent of the glaciers, while the extraction of height information is more challenging due to data quality and characteristics. This article discusses the potential of historical aerial images for glacier modelling. More specifically, it analyses the impact of their coverage, radiometric- and geometric accuracy, state of preservation and completeness on the photogrammetric workflow. The data set used consists of scans of 300 (analog) aerial images acquired between August and October 1954 by the U.S. Air Force with a Fairchild KF7660 camera over the entire Province of Trento. For the modelling of the glaciers, different techniques such as manual stereoscopic measurement and dense image matching were tested on sample glaciers and the results were analysed in detail. Due to local radiometric saturation in a large part of the glacial surfaces and other disturbances affecting the historical images (e.g. scratches, scanning errors, dark shadows), dense image matching did not produce any valuable results, and stereo plotting could be used only on images (or image parts) with acceptable quality. The derived Digital Terrain Models (DTMs) were compared with a reference DTM obtained with dense image matching from digital aerial images acquired in September 2015 with an UltraCam Eagle sensor, and, for some glaciers, to a DTM obtained with dense image matching from scanned aerial images acquired in September 1983 with a RC30 analog camera. The differences between 1954 and 2015 DTMs showed values up to $70-80 \mathrm{~m}$ in height and a behaviour that is confirmed by the models employed by the glaciology experts in Trento.
\end{abstract}

\section{MANUSCRIPT}

The retreat of the glaciers is one of the most evident manifestations of the ongoing climate change. The reduction of glacial masses has significant effects on the local water management for agriculture, in flood forecasting, in flood prevention, in the water supply and for electricity production (Kaser et al., 2010, Patro et al., 2018). Moreover, knowledge of the climatic parameters and the evolution of glaciers over the last century is the key to tune glacier models and estimating the expected "survival time" of the remaining glaciers (Maussion et al., 2019). The volume variation of a glacier is estimated by subtracting the glacier elevations measured at two different times, and converting the result into a mass change, thereby assuming the density in the different parts of the glacier.

Different methods exist to quantify the mass change of glaciers. The direct glaciological method is the only method based on insitu measurements (Østrem and Stanley, 1991). At a number of individual points the change in surface level is measured at two epochs and the gain (or loss), multiplied by ice or snow density, yields an estimate of the mass balance at that point. Winter gains (winter balance) are measured by probing the snow with avalanche probes; summer losses (summer balance), on the other hand, by recording the progressive protrusion of stakes driven into the ice along transects from top to glacier terminus. Density values for ice are assumed constant at $900 \mathrm{~kg} / \mathrm{m}^{3}$, while snow density is measured in snow pits (Østrem and Stanley, 1991). This method requires a strong commitment of personnel (mountaineers), time and resources, especially if the glacier surface is large, and has the disadvantage of providing discrete point information only on accessible areas. On the other hand, the accuracy of the measurements and the reading of the protrusion of the stakes is good, approximately $5 \mathrm{~cm}$.

Another method used for calculating the mass change of glaciers is the geodetic method (Cogley, 2009). Thereby, the digital terrain model (DTM) of a glacier at a certain epoch is derived from topographic maps, photogrammetry or airborne laser scanning (ALS) using satellite data or aerial data captured by manned or unmanned aircraft (Racoviteanu et al., 2009, Janke, 2013, Helfricht et al., 2014). The main advantage is that orthophotos and DTMs can be generated quickly in the office with reduced field work. The technological advances in digital photogrammetry in the last decade have also allowed the production of Digital Surface Models (DSMs, equivalent to DTMs on glaciers as there are no vegetation and no man-made objects) from digital aerial images with Dense Image Matching (DIM). These techniques have proved to be successful also on glaciated areas, if modern digital cameras and suitable overlaps are used for the image acquisition (Legat et al., 2016, Mölg and Bloch, 2017); they also have the great advantages of the lower cost compared to other technologies (i.e. airborne laser scanning) in case of new acquisitions, and the possibility to be employed on archived images with suitable overlaps and image quality. With respect to the platforms used for image acquisition, unmanned Aerial Vehicles (UAVs) are efficient only for mapping small areas of interest (typically $<1 \mathrm{~km}^{2}$ )

\footnotetext{
${ }^{*}$ Corresponding author
} 
with accuracies in the order of few centimetres (Immerzeel et al., 2014). Satellite images can cover large surfaces on a single orbit path, therefore with small or zero time variations, and with nominal ground resolution from $30 \mathrm{~cm}$ up to tens of metres. The GLIMS (Global Land Ice Measurements from Space) project, e.g., maintains a multi-temporal database with an extensive set of attributes of the world's glaciers, primarily extracted from data from optical satellite instruments (Kargel et al., 2014). A supplement to the GLIMS database is Randolph Glacier Inventory (RGI), which is intended to be a snapshot of the world's glaciers extension as they were near the beginning of the 21st century (RGI Consortium, 2017). The New Italian Glacier Inventory (Smiraglia and Diolaiuti, 2015) is a project realized by a large-scale analysis based on remote sensing and GIS techniques that have produced an update of the perimeters and morphometric data of all Italian glaciers. Theoretically positioned between UAV- and satellite-based approaches, aerial photogrammetry is an advantageous technique for the collection of images on glaciers. It ensures the complete coverage of single glaciers during a flight mission, and provides imagery at a ground resolution between 5 and $20 \mathrm{~cm}$ using current aerial cameras. Aerial flights can be planned for regular glacier monitoring at the desired ground resolution in specific periods of the year. Even inaccessible areas due to crevasses, supraglacial streams or avalanche risk can be surveyed photogrammetrically with accuracies in the decimetre- or centimetre range.

In particular, historical aerial images represent one of the oldest data sources covering glaciers extensively. They are therefore of great value for glacier monitoring and often provide the basis for area-, length-, volume- and mass change analysis. Hence, several studies worldwide used aerial images for chance analysis. The retreat of 132 Greenlandic glaciers could successfully be shown over a time period of 80 years by comparing the frontal position of marine- and land-terminating glaciers mapped in historic aerial images from the 1930s and in early and modern satellite images (Bjørk et al., 2012). A time series of glacier-mass changes in the Himalaya based on stereo imagery of satellites and areal images was constructed by (Bolch et al., 2019) where aerial images from 1984 were used to calculate a DTM of the glaciers. Historic aerial images from the 1950s were also used to determine detailed elevation and volume analysis of sixteen individual glaciers located in Antarctica (Fox and Cziferszky, 2008, Fieber et al., 2018). Another investigation in Antarctica was based on a vast dataset encompassing 30.000 historic aerial images dating back to the 1940s (Koblet et al., 2010). For one glacier in Sweden, DTMs and orthophotos were generated based on consistent photogrammetric processing of aerial photographs between 1959 and 1990 (Koblet et al., 2010). One key factor when working with historical aerial images on glaciers is image quality: the images were often captured for other purposes than glacier mapping (surveying of populated places or significant infrastructures, not for glaciers modelling) and with much lower radiometric dynamics and resolution than with today's technology. In this context, our article discusses the potential of historical aerial images for the extraction of DTMs on glaciers. Our focus lies on the quality assessment, with particular attention to coverage, radiometric and geometric accuracy, state of preservation and completeness, how these factors influence the standard photogrammetric workflow, and under which limitations DTMs and other 3D data can be extracted. The analysis is conducted on a set of aerial images acquired in 1954 by the U.S. Air Force over the entire Province of Trento in North Italy (area $6,208 \mathrm{~km}^{2}$ ), including several dozen glaciers with a total extension of about $32 \mathrm{~km}^{2}$ in 2015 (Figure 1).

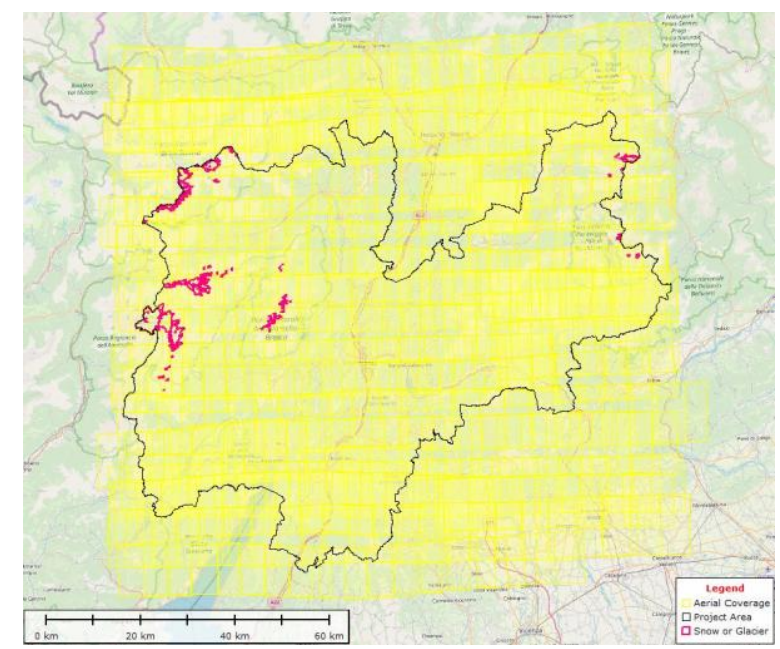

Figure 1. Aerial coverage (yellow) on the Province of Trento (black) and extension of glaciers (pink) in 1954.

The images were at disposal of the Glaciology group at the Museum of Science (MUSE) in Trento (Italy), and were processed by the Austrian company Vermessung AVT-ZT$\mathrm{GmbH}$ (AVT) with the aim of modelling the glacier surfaces.

The article is organized as follows: After the data analysis in Chapter 2, the methodology used to derive the georeferenced products is described in Chapter 3, and the results are discussed in Chapter 4. Conclusions close the work with lessons learned remarks and future investigations.

\section{DATA DESCRIPTION}

\subsection{Historical aerial images from 1954}

First aerial image flights in Europe started in the early $20^{\text {th }}$ century. In the first aerial photogrammetric missions, stability and shutter speed were technical challenges, but towards the end of the World War I, Sherman M. Fairchild developed a camera with the shutter located inside the lens system. This design significantly improved the quality of the images, and became standard for aerial camera systems over the next 50 years (Doyle, 1980, Baumann, 2019).

The aerial images used in this work over the Province of Trento were acquired during different aerial missions between August and October 1954 with three Fairchild analog cameras of type KF7660 with a photo size of $23 \mathrm{~cm} \times 23 \mathrm{~cm}$ and focal lengths of around $153 \mathrm{~mm}$ (Figure 2). As was common practice in analog aerial photography, the side information on the image frame includes the date and time of the flight, the lens type and the approximate altitude.

The scanned images were provided by the Instituto Geografico Militare (IGM) in Florence (Italy), and have a stated scan resolution of 2400 dpi. Given the flying height and the height ranges in the Province of Trento $(150 \mathrm{~m}-3500 \mathrm{~m})$, it is estimated that the mean ground resolution of the scanned images is around $0.60 \mathrm{~m}$ and the mean scale of the flight was about 1:55,000. The analysis of the image quality was conducted taking into account the following aspects:

Coverage. The Province, and in particular the glaciers, are fully covered by the aerial images. The flights were flown in EastWest direction, with an overlap of about $60 \%$ in flight direction and $30 \%$ between neighbouring strips (Figure 1). The coverage is suitable for aerial triangulation and orthophoto production in flat, hilly and mountain areas. 

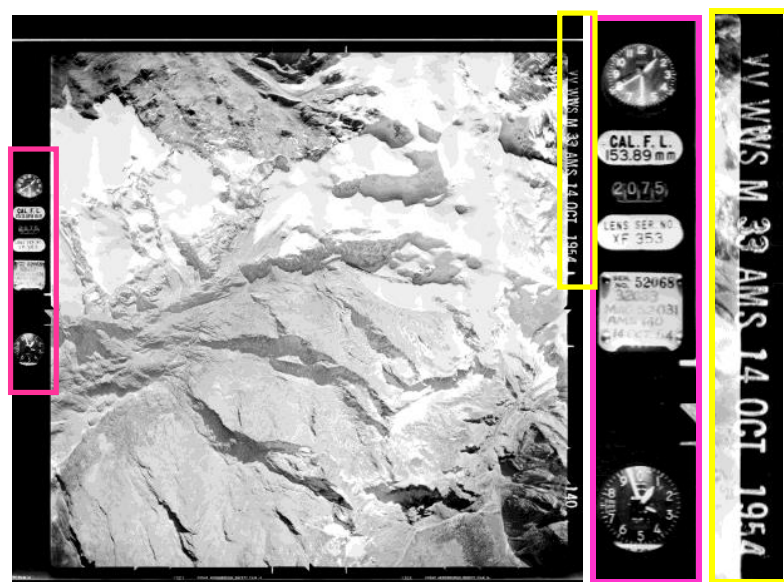

Figure 2. Example of scanned aerial image from 1954 over a glacial area together with zoomed views of the side information on the image.

Visibility. Some sensitive areas distributed across the entire Province like factories or military barracks were masked in the original photos with a black pencil or similar (Figure 3). The glaciated parts were not affected by any deletion.

Conservation. A deterioration of the paper prints over time is presumed. Additionally, the quality of preservation of the prints prior to scanning is in general poor. Scratches, cuts and signs of glue affect the majority of the images (Figure 4).

Scanning. During scanning, the analog photo is transferred to a digital data set, and this process further deteriorates the image quality. To preserve the original image quality, analog films should be scanned with photogrammetric scanners with geometric accuracy of a few microns and high radiometric dynamics. The images used in this work were scanned with non-photogrammetric equipment resulting in a lower geometric and radiometric quality of the digital images. In addition, some sort of mechanical errors are present too. They appear as missing lines of pixels or misalignments in linear features (Figure 3).

Although annoying, those errors did not prevent estimating the interior and exterior orientation of the images following rigorous photogrammetric procedures, and generating the orthophoto of the entire project area, as it will be explained in the next sections. However, those errors were affecting the generation of 3D products significantly. In addition, in the areas covered by glaciers, some other problems have to be mentioned:

Saturation. The flights were executed in meteorological conditions optimal for populated areas, with clear sky and high sun inclination. On an area covered by ice or fresh snow, such conditions cause strong reflections, resulting in saturation effects in the analog photos and, hence, in the scanned images. This effect occurs even on modern optical systems with incomparably better dynamic range, using optimized exposure times for such landscapes. In the historic images, the effect is sometimes limited to some pixels, but in some areas of the project, like the Adamello glacier, it affects large parts of the glaciers (Figure 5).

Contrast and dark shadows. The mountains in the Province of Trento, in particular in the Dolomites, are characterized by steep slopes, vertical walls and deep cirques. In these areas dark shadows are present. Due to the limited dynamic range of the images, shadows often appear as almost homogeneous black surfaces (Figure 6). As a result, the identification (and measurement) of any significant feature is almost impossible.

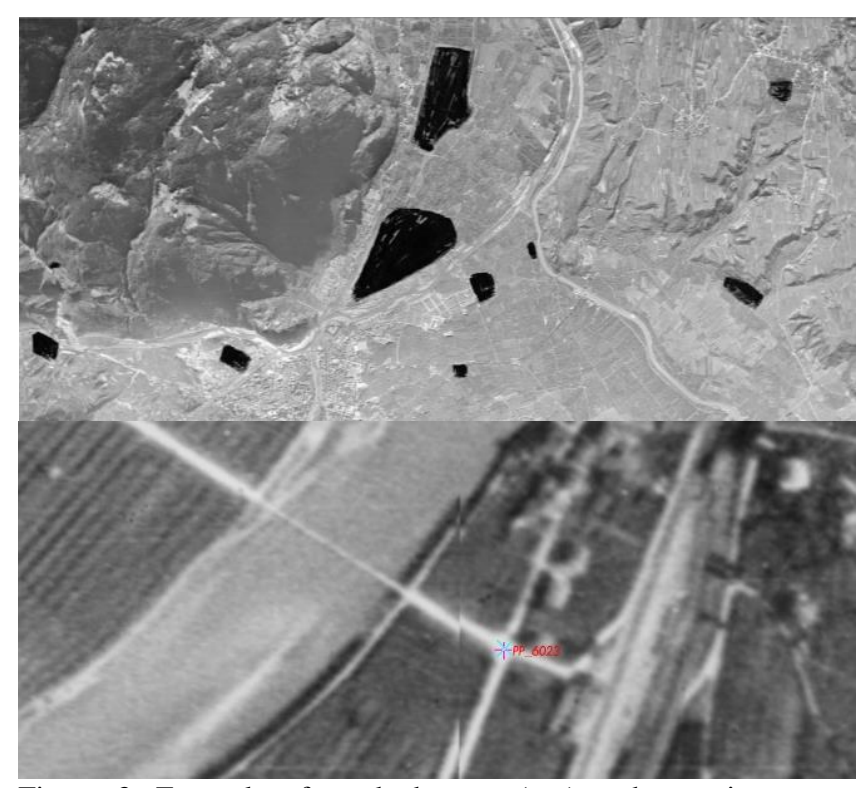

Figure 3. Example of masked areas (top) and scanning errors (bottom)

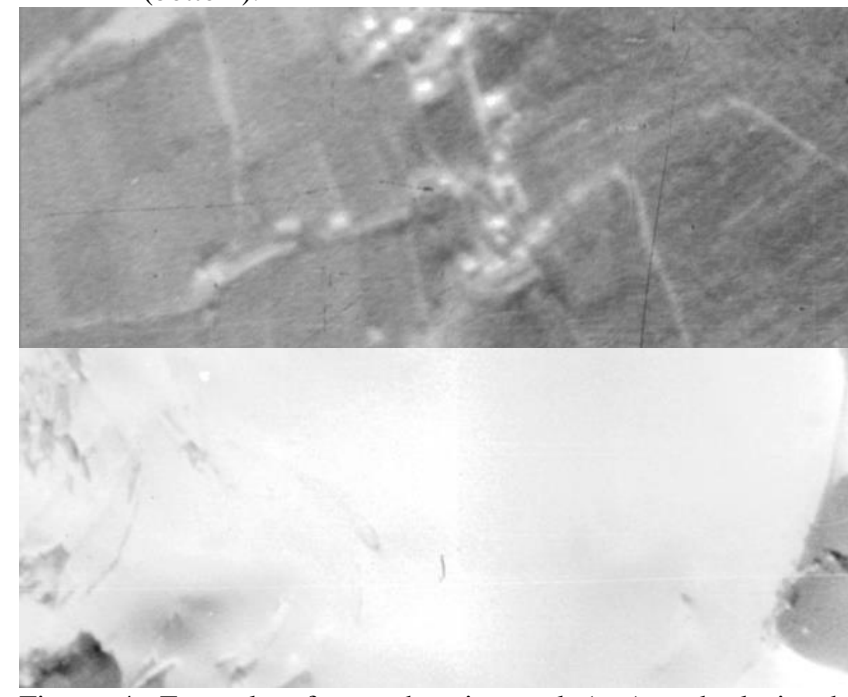

Figure 4. Example of scratches in rural (top) and glaciated (bottom) areas.

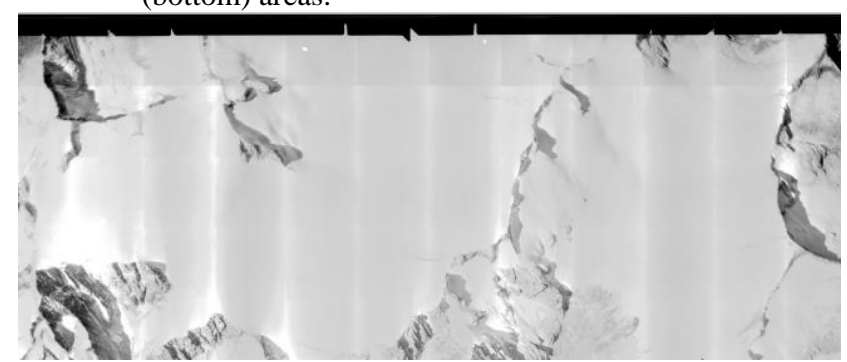

Figure 5. Example of saturation effects in 1954 images on large parts of glaciers.

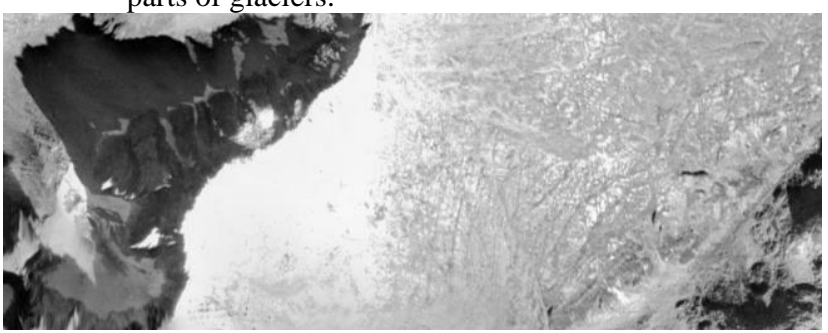

Figure 6. Example of dark shadows close to vertical surfaces in 1954 images. 


\subsection{Aerial images from 1983 and 2015}

Another flight available at the Glaciology Group of MUSE was acquired in September 1983 with an aerial film camera Leica RC30 (nominal focal length $150 \mathrm{~mm}$ ), with overlap 60\% - 30\% and photo scale about 1:40,000. For the purposes of the current work, a subset consisting of 126 images in 9 flight strips covering some glaciers of interest was used. The images were triangulated by AVT using Match-AT by Inpho / Trimble and processed in Agisoft for the automatic production of a DTM with grid spacing $50 \mathrm{~cm}$ by DIM and an RGB orthophoto with a ground-sampling distance (GSD) of $20 \mathrm{~cm}$.

Furthermore, in 2015 a DTM of the Trentino glaciers was generated by AVT with a digital image flight, and used as a basis for the glacier inventory of the Autonomous Province of Trento. The flight was executed in September 2015 using a large-format digital aerial camera UltraCam Eagle (focal length $100 \mathrm{~mm}$ ). The images have a mean GSD of $10 \mathrm{~cm}$ and large overlaps ( $80 \%$ forward, $60 \%$ between strips). For the 3D modelling of the glaciers, the images were first triangulated (an RMSE of about 0.5 pixels was achieved both in planimetry and height at the check points), then processed with DIM. As result, a DTM with grid spacing $50 \mathrm{~cm}$ (hereafter called DTM_2015) and an orthophoto in four bands (Red, Green, Blue, Near Infrared) with GSD $10 \mathrm{~cm}$ were produced. The use of a modern optical system for image acquisition and the flight parameters allowed modelling the glaciers almost on all the project areas. Saturation effects were not present, and DIM also provided valuable results in shadowed areas. As the flight was planned to cover the glacier state of 2015, the DTM and orthophoto do not cover the glacier state of 1954 completely. The 2015 products were used as reference for the assessment of the 3D models from 1954 in stable areas outside the glaciers and for change analysis.

\section{GLACIER MODELLING}

\subsection{Aerial triangulation and orthorectification}

The interior and exterior orientations of the images have to be retrieved before measurements can be performed with the images. The methodology for the interior orientation depends on the camera information available, in particular the calibration report. In case of our project, no calibration report was available for any of the three cameras, which is quite common for imagery from the first half of the $20^{\text {th }}$ century; only the focal length of the cameras (as printed on the image frames) and the scan resolution of the images (in dpi) were known. An operator measured manually the fiducial marks for a selection of aerial images of each camera, and used the average values as the fiducial marks' positions. The distortion parameters of each camera were then estimated in a bundle adjustment by minimizing the differences between the measured and the correct positions of the fiducial marks. The analysis of the behaviour of the standard deviations showed divergent film shrinkage between the images. The results are subject to some uncertainties, which cannot be exactly quantified for the following reasons. First, the fiducial marks were measured on images from a non-photogrammetric scanner, and scanning errors could not be compensated; additionally, the degree of film shrinkage within the original photos is unknown.

The aerial triangulation of the flight block was conducted using Match-AT. Due to the differences between the flight strips, partly due to the different flight days, the tie-point matching of the block as a whole was impossible. Therefore, tie points were measured automatically by matching on each strip separately and then the strips were connected manually to the adjacent one(s). A large number of ground control points (GCPs) were measured within the block. Suitable points were located at unchanged features like churches, road crosses or other (historic) buildings. The ground coordinates of the selected points were retrieved from previous projects carried out in 2015 in the project area, from topographic maps of the IGM, and from a public geodatabase of the Province (Figure 7).

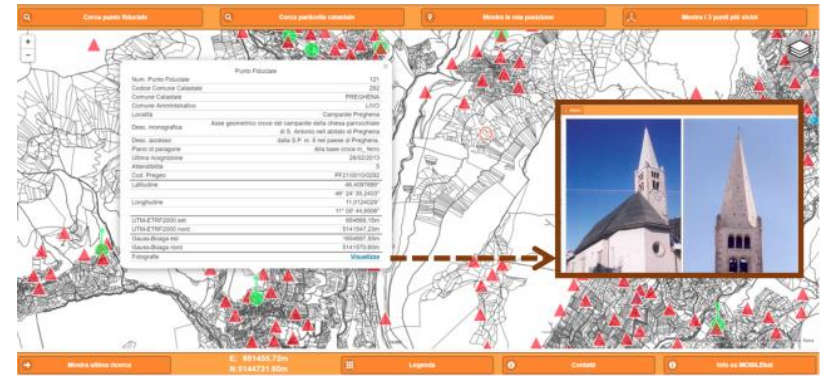

Figure 7. Selection of a GCP in the geodatabase of the Province of Trento.

The individual ground points were not always clearly identifiable within the images from 1954. This caused uncertainties in the measurements. The AT results, summarized in Table 1, confirm the significant uncertainties expected from the interior orientation and the quality of the aerial images. Due to the multitude of uncertainties, no reliable statement on the absolute accuracy can be made.

Table 1. Results of aerial triangulation of images from 1954. Mean standard deviation $(\sigma)$ of rotations, translations, terrain points and GCPs and Root Mean Square Error (RMSE) of GCPs.

\begin{tabular}{|c|c|c|c|}
\hline & $\begin{array}{c}\text { Omega } \\
{[\mathrm{deg} / 1000]}\end{array}$ & $\begin{array}{c}\text { Phi } \\
{[\mathrm{deg} / 1000]}\end{array}$ & $\begin{array}{c}\text { Kappa } \\
{[\mathrm{deg} / 1000]}\end{array}$ \\
\hline$\sigma$ rotations & 43.0 & 34.2 & 11.7 \\
\hline & East $[\mathrm{m}]$ & North $[\mathrm{m}]$ & Height $[\mathrm{m}]$ \\
\hline$\sigma$ translations & 5.8 & 6.9 & 6.1 \\
\hline$\sigma$ terrain points & 2.3 & 2.6 & 6.9 \\
\hline$\sigma$ GCPs & 1.5 & 1.2 & 1.6 \\
\hline RMSE GCPs & 1.5 & 1.2 & 1.4 \\
\hline
\end{tabular}

The orthophoto was generated with a target resolution of $1 \mathrm{~m}$ for the whole Province of Trento, using an ALS-based DTM from 2006. Figure 8 shows a detail of the orthophotos 1954, 1983 and 2015 on the Agola glacier.

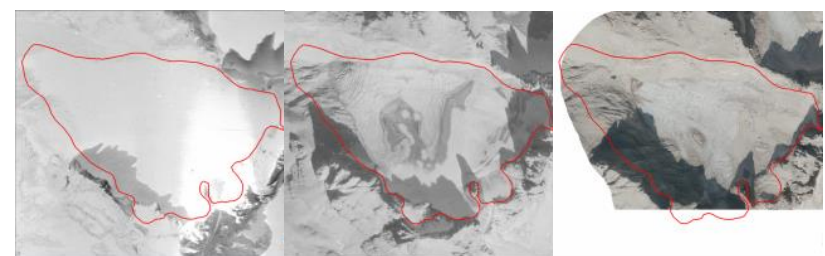

Figure 8. Orthophoto on the Agola glacier from 1954 (left), 1983 (center) and 2015 (right) aerial images. The glacier perimeter from 1954 is shown in red.

\subsection{Digital terrain modelling}

The choice of the methodology for the extraction of the height information from the historic aerial images is dictated by the flight characteristics and the image quality. For this reason 
different techniques were evaluated.

For the images from recent flights, DIM proved to be a successful technique for the modelling of glaciers. The method allows extracting point clouds of the surface through image correlation, with density down to the pixel level. The method is very powerful, but requires high overlap between the images and structured (i.e. non-homogenous) land covers to work automatically and successfully. Some glaciers were selected to test DIM, where the 1954 images had a lower presence of saturated areas. However, results were unsatisfactory even in these areas due to the presence of noise. In general it was concluded that the low radiometric quality of the images and the limited overlaps, did not allow automatic surface modelling on the full extension of any individual glaciers in the project area. It was then decided to abandon automatic methods and evaluate manual stereo plotting. Thereby, an expert operator manually measured mass points and break-lines in the stereo images, following the terrain morphology, and stored their 3D coordinates. The 3D measures were then interpolated and regularized in a raster grid. The higher the density of the measures, the better is the DTM representation. The method is time-consuming and expensive. Furthermore, it is essential that the operator is experienced and familiar with plotting on difficult surfaces such as glaciers to identify potential features. To investigate the usability of stereo plotting on the 1954 images, a test was performed on one glacier in the OrtlesCevedale group, called Careser glacier that has been classified as one of the Italian reference glaciers by the World Glacier Monitoring Service, for the longest series of mass balance data beginning in 1967. In Figure 9 (left) the glacier outlines delineated in the 1954 and 2015 images are visible. Mass points were plotted in stereo in two distinct sessions by the same operator but on two different days called Stereo1 and Stereo2 (Figure 9), and two independent DTMs were generated from the two sessions.

The comparison between Stereo1 and Stereo2 DTMs is given in Figure 10. The mean difference is $3.65 \mathrm{~m}$, with a standard deviation of $7.10 \mathrm{~m}$. The two DTMs show a general agreement (white, yellow and light blue differences are below $\pm 5 \mathrm{~m}$ ), however, with greater differences in the East part. The main reason for these deviations is the difficult identification of features suitable for stereoscopic measurements. This region is indeed characterized by a very homogenous glacier surface, bright colours, small surface variation, pronounced snow cover and local oversaturation (Figure 11 right). The stereoscopic method is therefore uncertain within such areas, but achieves better results at lower altitudes, where the surface is more heterogeneous and more details can be identified (Figure 11 left). In such conditions, the stereoscopic method can be considered a reliable method for 3D information extraction. In case of the 1954 flight, we estimated a relative accuracy in the range of 1-2 $\mathrm{m}$ in planimetry and 3-5 $\mathrm{m}$ in height for the stereo measurements in glaciated areas where features could be identified. The comparison with DTM_2015 (Figure 10 right) showed height loss at the glacier of up to $70 \mathrm{~m}$ in areas with reliable surface structuring; the numbers have been judged plausible by the glaciology experts.

Based on the conclusions of the test on the Careser glacier, the work proceeded with the terrain modelling of all glaciers with stereo plotting and the generations of DTMs with grid spacing $10 \mathrm{~m}$. As expected, in some regions the image quality did not allow stereo measurements with sufficient density for continuous surface modelling. In these cases, only the discrete punctual measurements were delivered to the glaciologists at MUSE. This 3D information, although not continuous, is anyway important for the height change analysis from 1954.

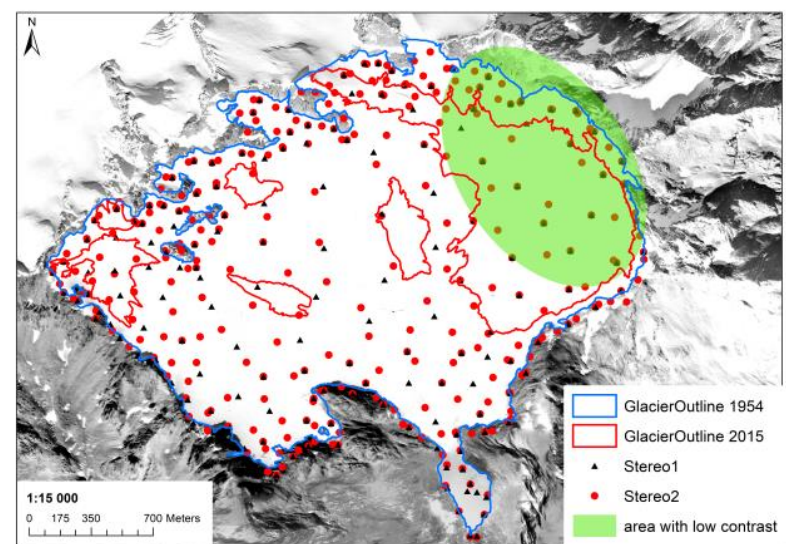

Figure 9. 3D information extraction on Careser glacier. Outlines of the glacier in 1954 (blue) and 2015 (red). Mass points measured in two different sessions (black triangles and red points) and an area wide low contrast (green ellipse).
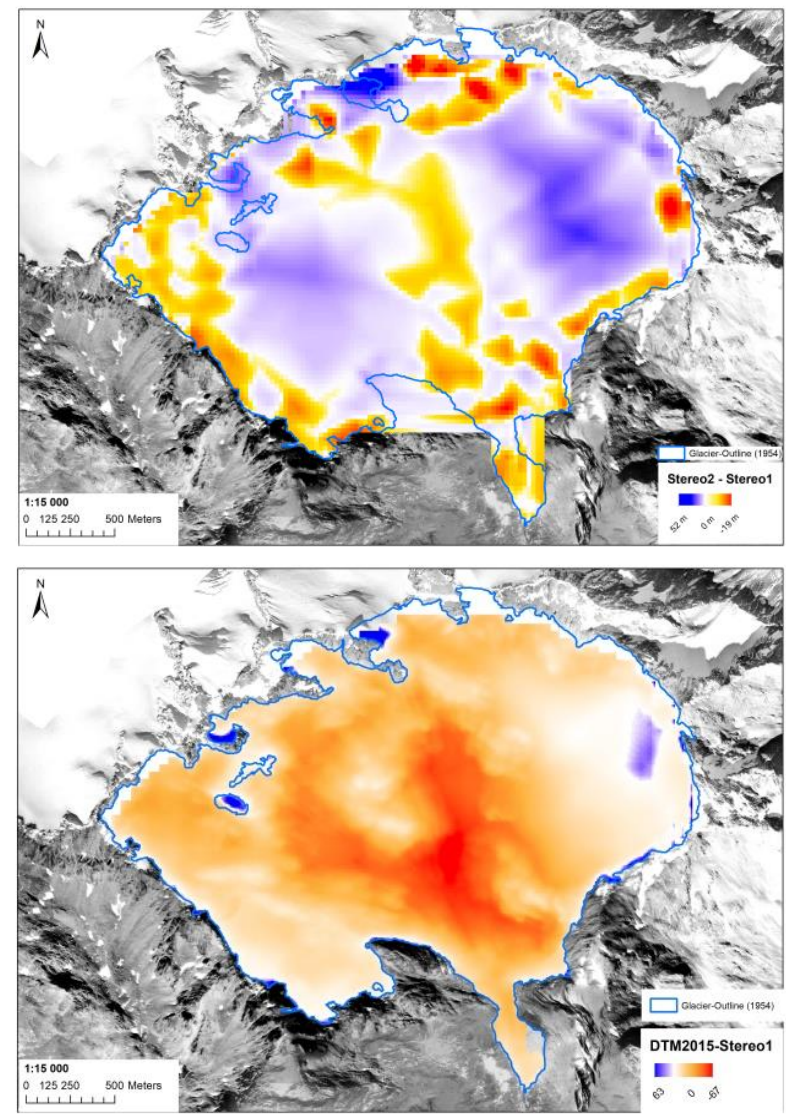

Figure 10. 3D analysis on Careser glacier. Top: difference between DTMs from two independent measurements Stereo1 and -2 in 1954 images. Bottom: difference between the DTM from 2015 and 1954 (Stereo1). Note the different colour range of the two figures.

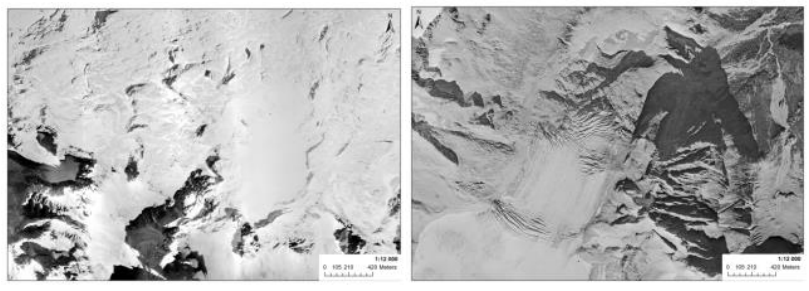

Figure 11. Example of areas where stereo plotting is not possible (left) and possible (right). 


\section{DISCUSSION}

To evaluate the 2D/3D information of glaciers extracted from the 1954 images, the glacier outlines and terrain models were compared to the available data from other years, and the changes were matched to the prediction models used by the glaciology experts. The first assessment of glacier changes was performed through the analysis of the outline reductions. The Glaciology group had at disposal the perimeters from $19^{\text {th }}$ century (Carturan et al., 2014), from the years 1983, 2003 and 2015, the Randolph Glacier Inventory and the New Italian Glacier Inventory. The outlines of the glaciers in 1954 were first digitized in the orthophoto but this was only possible for very clear glacier boundaries (i.e. when glacier ice is directly confined by solid bedrock). The ortho-based digitalization has proved limitations in the following situations: 1) poor image quality (low contrast, dark shadows); 2) DTM-based errors and 3) unclear glacier boundaries due to debris, permanent snowfields, fresh snow, and/or hard shadow. In some of these cases the 3D stereo measurements could facilitate the digitalization of glacier outlines and increase their accuracy. For example, in case of Careser glacier (Figure 9), the glacier tongue was erroneously interpreted as a lake by the ortho-based digitalization, and could be correctly assigned to the glacier via stereo measurements. The comparison with the other data underlined the validity of the orthophotos for metric measurements, confirming the shrinking that the glaciers have suffered from the end of the 50's until today (Figure 12).

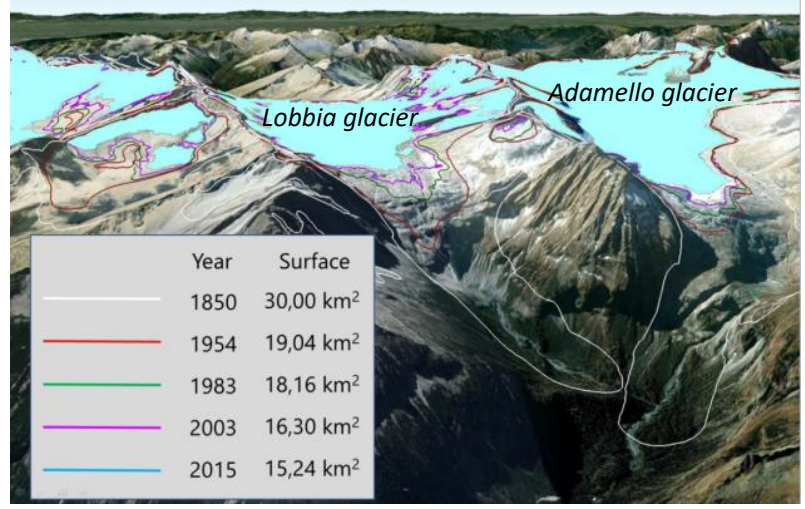

Figure 12. Temporal analysis of glacier perimeters and comparison between extents in 1850, 1954, 1983, 2003 and 2015 of Adamello and Lobbia glaciers.

The DTMs from 1954 were compared to more recent 3D data, represented by the DTM_2015 or the SRTM from 1990, where the 2015 coverage was not complete. The surface models were compared by calculating the height differences (the newer minus the older one) and analysing the distribution of the values in relation to the source data quality and the local geomorphology. The analysis was executed for all glaciers separately. As an example, Figure 13 shows the difference maps in correspondence of Camosci glacier (a) and Settentrionale di Cornisello glacier (b) in the Presanella Group, between the DTM obtained with stereo measurements in 1954 images and the DTM_2015.

In almost all glaciers, negative and positive peaks up to $50 \mathrm{~m}$ were observed, located in areas that could not be modelled correctly due to dark shadows (in particular close to vertical surfaces), saturation and/or scratches. Those areas were classified as insignificant and excluded from the analysis.

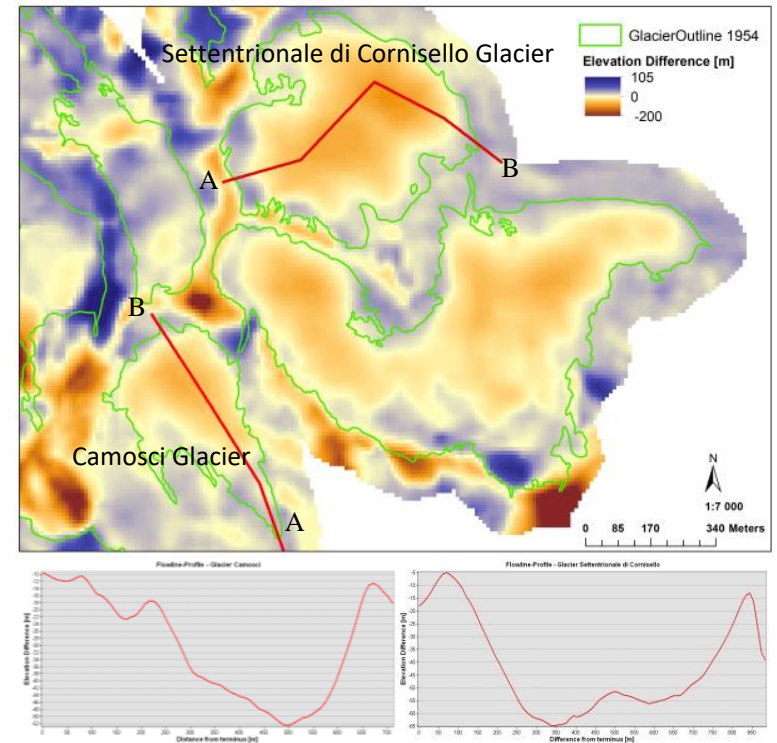

Figure 13. 3D change analysis (1954, 2015). (Left) Camosci glacier, (Right) Settentrionale di Cornisello glacier in the Presanella Group. Top: 2D difference maps, bottom: height profiles along transects from points A to B. (Please note that apparent positive changes are not due to increased glacier thickness but interpolation effects over low-contrast areas.)

Along the borders of some vertical surfaces, very large suspicious differences in height were observed, but they were classified as false changes after a detained analysis. Indeed it is well known that the interpolation of the mass points and break lines for the generation of a DTM introduces errors at surface discontinuities (Figure 14 left); these errors can produce wrong results when one DTM is compared with another one (Kraus et al., 2006, Wilson, 2012 and Figure 14 right). In case of the 1954 images, the interpolation error is evident in correspondence of steep mountains, accompanied by areas in the images with very low contrast, where the density of stereoplotting was irregular and/or very low. In these situations the DTM grid width of $10 \mathrm{~m}$ is too small compared to the separation between neighbouring measurements. Although the stereo measurements might have been correct, the modelling errors in the interpolated DTM from sparse points led to large differences between the true terrain and its digital representation. In addition, when two surface models are compared, it should be taken into account that there could be a planimetric misalignment between them $(\Delta \mathrm{x}$ in Figure 14 right), because the two models are derived with methods and data having different intrinsic accuracies. In case of the DTMs compared in the current analysis, the planimetric shift is in the order of some meters. In a landscape characterized by the presence of steep surfaces and discontinuities, the elevation differences alone may not truly represent the surfaceto-surface distance, and a large height difference would result $(\Delta \mathrm{h})$, even if the height values may be correct and the surface distance smaller (d). 

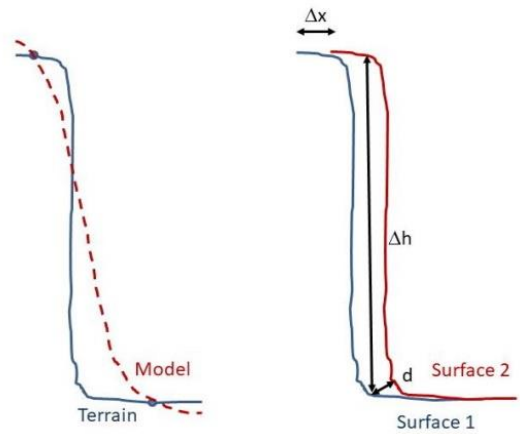

Figure 14. The sub-optimality between 1D elevation difference $(\Delta \mathrm{z})$ and the spatial distance $(\mathrm{d})$.

Other areas excluded from the analysis were those where the measurement uncertainties were larger than the assumed volume changes. This situation occurred mainly at very small glaciers where the point measurements were particularly difficult. In the majority of the glaciers, some parts were covered by snow without structure, especially at higher altitudes. Here the stereo measurements were more problematic, which was reflected by anomalous difference values compared to DTM_2015. Those areas were excluded from volume-change calculations.

In the remaining areas, the elevation changes followed a reasonable behaviour with plausible values and a common trend could be observed for glaciers belonging to the same region; in such cases, the data were considered reliable for the calculation of the temporal mass changes and other related analysis.

The changes were also analysed through the profiles of the height differences along transects of interest, drawn from the terminus (downstream, A) to the top (upstream, B) of the glaciers. As an example, in Figure 13 the profiles in correspondence of Camosci glacier (a) and Settentrionale di Cornisello glacier (b) in the Presanella Group, between the DTM obtained with stereo measurements in the 1954 images and DTM_2015, are plotted.

The two profiles have a similar behaviour, which can be explained by the model shown in Figure 15. The starting point of each profile is located on emerging rocks in correspondence of the front of the glacier (downstream, point A in Figure 13). Here the surface height has not changed very much over time, which is correctly reflected by a profile value close to zero. Moving from here along the transect, the difference between the surface heights in 2015 and 1954 increases to a local maximum (maximal difference in height between 2015 and 1954), which corresponds to the location of the front of the glacier in 2015. Then the height difference begins to decrease along the transect; in correspondence of the highest altitudes (upstream, point B in Figure 13), the value of the profile is small, meaning that the thickness of the glacier has not changed significantly.

For Careser glacier, the mass balance determined by the glaciological method from 1967 to 2015 has returned a total loss of $58 \mathrm{~m}$ of ice. This value is coherent with the mass loss of $46 \mathrm{~m}$ obtained by difference DTM_2015 and the 3D geospatial measurements from 1954 discussed in this work.

The behaviour is visible also by comparing the DTMs from 2015 and 1983. Figure 16 shows an example for Agola glacier. The maximal difference is $75 \mathrm{~m}$, which is in line with the predictions by the glaciologists.

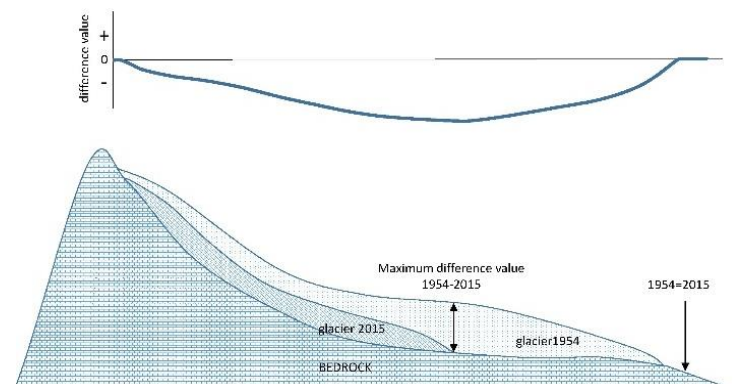

Figure 15. Values of the difference in altitude along a transect from upstream to downstream. The greatest difference is where the glacier terminus is today.
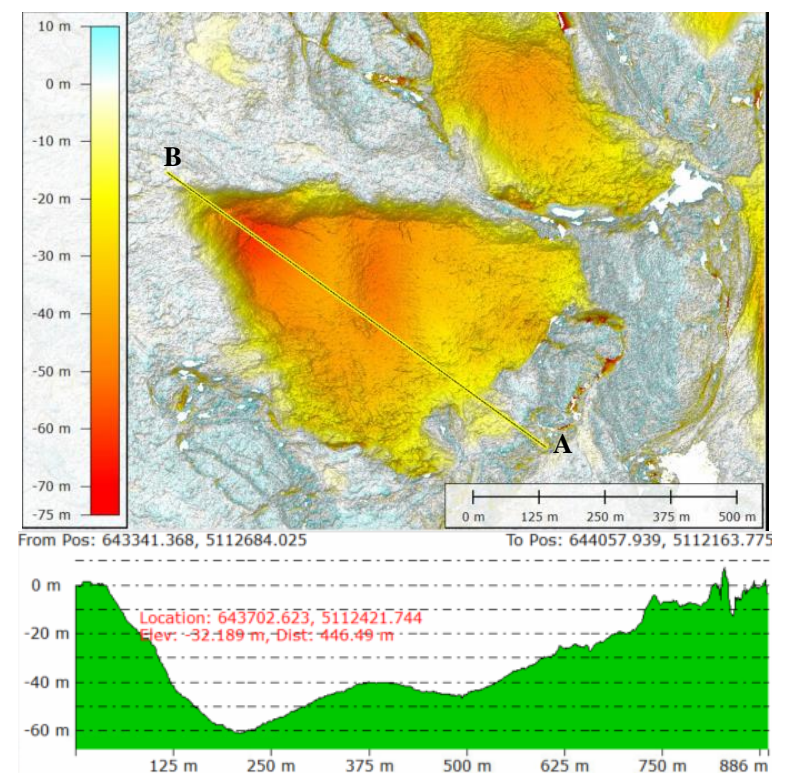

Figure 16. 3D change analysis $(1983,2015)$ on Agola glacier along a transect from points $\mathrm{A}$ to $\mathrm{B}$ and in a 2D map.

\section{CONCLUSIONS}

The aim of the work was to investigate the potential of historical aerial images acquired in 1954 by the U.S. Air Force for 3D information extraction on the glaciers in the Province of Trento (Italy). The analysis highlighted the low quality of the scanned aerial photos due to different reasons. First, the flight was planned to scan populated areas or sensitive targets, therefore it was executed during sunny days with clear sky. On glaciated areas, covered by ice or freshly snowed surfaces, the high reflectance, combined with low radiometric dynamics, produced saturated areas or low contrast areas (i.e. dark homogeneous shadows). In addition, the film scanning was not executed with a photogrammetric scanner which also contributes to a part of the loss of quality and content. Some mechanical errors and damages on the images (e.g. scratches) were present too. These problems affected the photogrammetric workflow in terms of achieved accuracy, but did not prevent performing an aerial triangulation and generating an orthophoto on the entire Province of Trento, including the glaciers. As expected, the poor image quality had more critical effects on the $3 \mathrm{D}$ surface modelling of the glaciers. Indeed, trials performed with DIM did not give any reliable results, although the same methodology had produced very satisfactory results on the same glaciers with images acquired in 1983 and 2015, and 
on other glaciers with aerial flights from the same historical period. The low image quality, in particular the local presence of large saturated and low-contrast areas, even affected the potential to model the glaciers manually with stereoscopic measurements in some regions. Nevertheless, a number of glaciers were modelled, and the heights compared to reference surfaces from more recent years. The results were critically discussed, concluding that in areas with acceptable image quality, significant volume changes can be detected and used for glaciological evaluations.

\section{REFERENCES}

Baumann, P., 2019. Aerial Photography: History and Georeferencing. The Geographic Information Science \& Technology Body of Knowledge (2nd Quarter Edition), John P. Wilson (Ed.).

Bjørk, A., Kjær, K., Korsgaard, N. et al., 2012. An aerial view of 80 years of climate-related glacier fluctuations in southeast Greenland. Nature Geoscience, 5, 427-432.

Bolch, T., Pieczonka, T., Benn, D. I., 2010. Longest time series of glacier mass changes in the Himalaya based on stereo imagery. The Cryosphere Discussions 4(4), 2593- 2613.

Carturan L., Baroni C., Carton A., Cazorzi F., Dalla Fontana G., Delpero C., Salvatore M. C., Seppi R., Zanoner T., 2014. Reconstructing fluctuations of La Mare Glacier (Eastern Italian Alps) in the Late Holocene: new evidence for a Little Ice Age maximum around 1600 AD. Geografiska Annaler, Series A Physical Geography, 3, 287-306.

Cogley, J. G., 2009. Geodetic and direct mass-balance measurements: comparison and joint analysis. Annals of Glaciology, 50, 96-100.

Doyle, I., 1980. Sherman Mills Fairchild: Memorial Address. Photogrammetric Eng. and Remote Sensing, 46(7), 923-936.

Fieber, K. D., Mills, J. P., Miller, P. E., Clarke, L., Ireland, L., Fox, A., J., 2018. Rigorous 3D change determination in Antarctic Peninsula glaciers from stereo WorldView-2 and archival aerial imagery. Remote Sensing of Environment, 205, 18-31.

Fox, A. J. and Cziferszky, A., 2008. Unlocking the time capsule of historic aerial photography to measure changes in Antarctic Peninsula glaciers. Photogrammetric Record, 23(121), 51- 68.

Helfricht, K., Kuhn, M., Keuschnig, M., Heilig, A., 2014. Lidar snow cover studies on glaciers in the Ötztal Alps (Austria): comparison with snow depths calculated from GPR measurements. The Cryosphere, 8, 41-57.

Janke, J. R., 2013. Using airborne LiDAR and USGS DEM data for assessing rock glaciers and glaciers. Geomorphology, 195, 118130.

Kargel, J.S., G.J. Leonard, M.P. Bishop, A. Kaab, B. Raup (Eds), 2014. Global Land Ice Measurements from Space (Springer-Praxis) ISBN: 978-3-540-79817-0.

Kaser, G., Grosshauser, M., Marzeion, B., 2010. Contribution potential of glacier to water availability in different climate regines. P. Natl, Acad. Sci. USA, 107, 20223-20227.

Koblet, T., Gartner-Roer, I., Zemp, M., Jansson, Pl, Thee, P., Haeberli, W., Holmlung, P., 2010. Reanalysis of multi-temporal aerial images of Storglaci" aren, Sweden (1959-99) - Part 1:
Determination of length, area, and volume changes. The Cryosphere, 4, 333-343.

Kraus, K., Karel, W., Briese, C., Mandlburger, G., 2006. Local accuracy measures for digital terrain models. The Photogrammetric Record, 21(116), 342-354.

Immerzeel, W.W., Kraaijenbrink, P.D.A., Shea, J.M., Shrestha, A.B., Pellicciotti, F., Bierkens, M.F.P., de Jong, S.M. Highresolution monitoring of Himalayan glacier dynamics using unmanned aerial vehicles. Remote Sensing of Environment, 150, 93-103.

Legat, K., Moe, K., Poli, D., Bollmann, E., 2016. Exploring the potential of aerial photogrammetry for 3D modelling of high-alpine environments. Int. Arch. Photogramm. Remote Sens. Spatial Inf. Sci., XL-3/W4, 97-106.

Maussion, F., Butenko, A., Eis, J., Fourteau, K., Jarosch, A.H., Landmann, J., Oesterle, F., Recinos, B., Rothenpieler, T., Vlug, A., Wild, C.T., Marzeion, B., 2019. The Open Global Glacier Model (OGGM) v1.1. In: Geoscientific Model Development 12(3), 909 931.

Mölg, N., Bloch, T., 2017. Structure-from-Motion Using Historical Aerial Images to Analyse Changes in Glacier Surface Elevation. Remote Sensing, 9(10), 1021.

Østrem, G. and Stanley, A., 1991. Glacier mass balance measurements. A manual for field work. Geographisches Institut Universitat Zurich, NHRI Science Report, 4, 234.

Patro, E.R., De Michele, C., Avanzi, F., 2018. Future perspectives of run-of-the-river hydropower and the impact of glaciers' shrinkage: The case of Italian Alps. Appl. Energy, 231, 699-713.

Racoviteanu, A. E.; Paul, F.; Raup, B.; Khalsa, S.J. S.; Amstrong, R., 2009. Challenges and recommendations in mapping of glacier parameters from space: results of the 2008 Global Land Ice Measurements from Space. Annals of Glaciology, 50, 53-69.

RGI Consortium, 2017. Randolph Glacier Inventory - A Dataset of Global Glacier Outlines: Version 6.0: Technical Report, Global Land Ice Measurements from Space, Colorado, USA. DOI: https://doi.org/10.7265/N5-RGI-60.

Smiraglia, C., Diolaiuti, G., 2015. The New Italian Glacier Inventory. Ev-K2-CNR Publ., Bergamo.

Wilson, J. P., 2012. Digital terrain modeling. Geomorphology, 137(1), 107-121. 